\title{
Interpretation Criteria for Comparative Intradermal Tuberculin Test for Diagnosis of Bovine Tuberculosis in Cattle in Maroua Area of Cameroon
}

\author{
J. Awah-Ndukum, ${ }^{1}$ J. Temwa, ${ }^{1}$ V. Ngu Ngwa, ${ }^{1}$ M. M. Mouiche, ${ }^{1}$ \\ D. Iyawa, ${ }^{2}$ and P. A. Zoli ${ }^{1}$ \\ ${ }^{1}$ School of Veterinary Medicine and Sciences, University of Ngaoundéré, BP 454, Ngaoundéré, Cameroon \\ ${ }^{2}$ Regional Delegation of Livestock, Fisheries, Animal Industries, Far North Region, Cameroon \\ Correspondence should be addressed to J. Awah-Ndukum; awahndukum@yahoo.co.uk
}

Received 5 April 2016; Revised 5 July 2016; Accepted 11 July 2016

Academic Editor: Francesca Mancianti

Copyright (C) 2016 J. Awah-Ndukum et al. This is an open access article distributed under the Creative Commons Attribution License, which permits unrestricted use, distribution, and reproduction in any medium, provided the original work is properly cited.

\begin{abstract}
Intradermal tuberculin test (TST) is the choice method for diagnosis of bovine tuberculosis (Tb) in live animals. This work was done to assess the performance of single intradermal comparative cervical tuberculin (SICCT) test in randomly selected cattle in Maroua, Cameroon, against detection of $\mathrm{Tb}$ lesions and detection of $\mathrm{Tb}$ lesions plus acid fast bacilli in lesions. While $22.28 \%$ of slaughtered cattle presented $\mathrm{Tb}$ lesions at meat inspection, detection rates of anti-bovine- $\mathrm{Tb}$ antibody, $\mathrm{Tb}$ lesions, and $\mathrm{Tb}$ lesions plus acid fast bacilli were $68.57 \%, 32.95 \%$, and $22.35 \%$, respectively. SICCT-bovine-Tb positive cattle were $35.29 \%, 29.41 \%, 25.88 \%$, $24.7 \%$, and $21.18 \%$ at $\geq 2 \mathrm{~mm}, \geq 2.5 \mathrm{~mm}, \geq 3 \mathrm{~mm}, \geq 3.5 \mathrm{~mm}$, and $\geq 4 \mathrm{~mm}$ cut-offs, respectively. Higher sensitivity and predictive values were obtained at severe interpretations. The best performance was at $\geq 3 \mathrm{~mm}$ and $\geq 3.5 \mathrm{~mm}$ cut-offs. Against detection of Tb lesions, $\geq 3 \mathrm{~mm}$ and $\geq 3.5 \mathrm{~mm}$ showed sensitivity of $67.8 \%$ and specificity of $94.7 \%$ and $96.5 \%$, respectively. For detection of Tb lesions accompanied with acid fast bacilli in lesions, $\geq 3 \mathrm{~mm}$ and $\geq 3.5 \mathrm{~mm}$ showed sensitivity of $89.4 \%$ and specificity of $92.4 \%$ and $93.9 \%$, respectively. These findings revealed that interpretations of SICCT-bovine-Tb should be at $\geq 3 \mathrm{~mm}$ and/or $\geq 3.5 \mathrm{~mm}$ cut-offs. Severe interpretation of TST is essential for optimal diagnosis of bovine Tb in cattle in Maroua, Cameroon.
\end{abstract}

\section{Introduction}

Bovine tuberculosis $(\mathrm{Tb})$ is a major chronic bacterial disease of animals and humans caused by Mycobacterium bovis. Though zoonotic, bovine $\mathrm{Tb}$ is neglected and underinvestigated in Sub-Saharan Africa including Cameroon $[1,2]$. In areas where bovine $\mathrm{Tb}$ is endemic and not controlled or partially controlled, human $\mathrm{Tb}$ due to $M$. bovis may occur resulting from ingesting contaminated fresh milk and meat products and by inhaling cough spray from infected cattle [3-8]. Widespread bovine $\mathrm{Tb}$ in cattle has been diagnosed in some parts of Cameroon following comparative cervical tuberculin test, detection of Tb lesions during abattoir slaughter meat inspection, acid fast staining of bacilli, and molecular analysis of cultured isolates $[1,9,10]$. Also, M. bovis in human has been reported in the West and Northwest Regions of Cameroon [11, 12].
Bovine $\mathrm{Tb}$ has significant impact on international trade of livestock and animal products [13]. Intradermal tuberculin skin test (TST) is the international choice method for field diagnosis of bovine $\mathrm{Tb}$ in live animals and the World Organisation for Animal Health (OIE) recommended difference between the increases in skin thickness for the test to be positive should be at least $4 \mathrm{~mm}$ after 72 hours [13]. However, the performance of TST is affected by environmental and host factors and the nature of the tuberculin used [14-19]. A perfect cut-off point in a specific geographic area or country may not be useful in another environment or another country $[14,17,20]$ and the ability of the test to accurately predict true positive disease status depends on its sensitivity, specificity, and prevalence of the disease in the population tested [14]. The OIE recommended cut-off value was established mainly in developed countries for Bos taurus cattle and different 
cut-off values are applied according to a particular country's disease status and objective of its disease control programme [17]. Severe interpretations have been used in Chad, Ethiopia, and Tanzania $[15,17,21-23]$ and in regions or herds where $M$. bovis infection had been confirmed based on the discretion of the veterinarian [17].

TST together with slaughter of positive reactors to examine for Tb lesions; culture of suspected $\mathrm{Tb}$ specimens; and other modern diagnostic techniques (e.g., gamma-interferon, ESAT-6 tests, and serologic and fluorescence polarization assays) have been compared and are being validated for maximum diagnosis of bovine $\mathrm{Tb}$ in cattle in various environmental conditions [14, 24-28]. This study was therefore carried out to estimate the prevalence of bovine $\mathrm{Tb}$ and assess the diagnostic performance of TST in the diagnosis of bovine $\mathrm{Tb}$ zebu cattle in Maroua area of Cameroon.

\section{Materials and Methods}

2.1. Study Area and Population. Cattle from the livestock markets in the environs of Maroua destined for slaughter at the Makabaye abattoir were sampled for the study. About twenty cattle are slaughtered daily in the Makabaye abattoir which provides beef to inhabitants of Maroua city and neighbouring areas $\left(10^{\circ} 30^{\prime}-10^{\circ} 40^{\prime} \mathrm{N}\right.$ and $\left.14^{\circ} 20^{\prime}-14^{\circ} 30^{\prime} \mathrm{E}\right)$. A TST bovine $\mathrm{Tb}$ prevalence rate of $4.67 \%(3.89 \%-5.44 \%)$ recorded by Awah-Ndukum et al. [29] in the highlands of Cameroon using OIE recommended standards was used to estimate the number of cattle required to detect at least one positive reactor with $95 \%$ confidence and a desired precision of $\geq 5 \%$ as previously described [30]. The selection of cattle for the study was based on haphazard arrival of animals at the abattoir and on random-number generation method of cattle owners from the daily abattoir records whose animals were judged as fit to be slaughtered. However, cattle used for the TST performance study were animals that were judged as fit to be slaughtered and were not slaughtered until at least 72-hour stay at the abattoir.

2.2. Detection of Bovine Tuberculosis. During November 2013 to March 2014, blood was collected by venopuncture of the jugular vein from 175 randomly selected cattle intended for slaughter to extract serum for lateral flow assay of anti-BTb antibody (Anti-Bovine $\mathrm{Ab}^{\circledR}$ ). Single intradermal comparative cervical tuberculin (SICCT) skin test was done on 86 random cattle of the 175 selected animals [13] that were slaughtered at least 72 hours later. Following slaughter of these 175 animals, intensive meat inspections were carried out by JT assisted by veterinary staff of the abattoir based on the government's legislation regulating veterinary health inspection and notification of contagious animal diseases [31]. Evidence of pathologies was also supported by postmortem examination of carcasses as earlier described [32-34]. Briefly, the inspection procedure employed visual examination and palpation of the lungs, liver, and kidneys, lymph nodes of the thoracic and head regions, the mesenteric lymph nodes, and other lymph nodes of the body and various other parts/organs of the carcass.
The sera were extracted and stored at $-20^{\circ} \mathrm{C}$ until analysis was carried out. Similarly, 68 tissues specimens, with suspicious TB lesions (53 thoracic and 7 abdominal lymph nodes and 8 liver tissues) from the 86 SICCT bovine Tb cattle of the 175 slaughtered zebu cattle in the study were collected into sterile plastic containers and also stored at $-20^{\circ} \mathrm{C}$ for up to two months before analysis. Individual animal information such as age estimated by examining the incisors [35], sex, breed [31,36], and body condition scores [37] was recorded during blood collection. Grinding of TB lesions [38] and direct smear microscopy with Ziehl-Neelsen (ZN) staining for confirmation of acid fast tubercle bacilli and lateralflow-based rapid test for detection of antibodies in serum were done following standard procedures $[13,39-41]$ and as described by manufacturer (Anigen Bovine $\mathrm{Tb} \mathrm{Ab}^{\circledR}$, BioNote Inc., Korea). Briefly, in the ready-to-use disposable lateral flow kit, $10 \mu \mathrm{L}$ of test serum was poured into the sample well and, after 1 minute, 3 drops of developing buffer (provided as part of the kit) were placed in the buffer well. The result was interpreted after 20 minutes. The presence of two purple coloured bands within the result window, the test area and control line, indicated antibodies positive result whereas no band in the test area in addition to a visible control purple line was negative. An invalid test was one where no coloured band was visible within the result window. The appearance of a control colour band, for positive or negative assays, indicated that the test was working properly.

Risk assessments of the project were performed by the researchers to avoid hazards to all persons and animals involved in the project. Ethical clearances were obtained from the required authorities before carrying out the study. The purpose of the study was explained to the targeted participants usually with the assistance of resident veterinarians, local leaders at the abattoir, and or trusted intermediaries. An animal was tested after an informed consent was given by the owner. Apart from minor jugular vein puncture for blood collection, intradermal injections of avian and bovine tuberculin, and procedural restraining manipulations for safety purposes, the animals were not subjected to suffering. Slaughtering and dressing of cattle carcasses were done as described by the Cameroon veterinary services [31]. All laboratory analyses including $\mathrm{ZN}$ staining were carried out in a laboratory equipped with a category II Biosafety cabinet.

2.3. Data Analysis. The data were entered into Microsoft Excel and then transferred to SPSS 20 and R software. Frequency distributions of bovine $\mathrm{Tb}$ were generated for the different diagnostic techniques. The Chi-square test was used to evaluate the sensitivity of TST and assess various associations. The ROC (Receiving Operating Characteristic) analysis was also used to evaluate diagnostic performance of TST at different cut-off points [30].

\section{Results}

3.1. Prevalence of Bovine Tuberculosis. Over $22.28 \%$ (164) of 736 cattle slaughtered at Makabaye-Maroua during the study period presented macroscopic $\mathrm{Tb}$ lesions at meat inspection. The cattle with Tb lesions were distributed as follows: 12 of 123 
(9.76\%) male animals, 152 of $613(24.80 \%)$ female animals, 44 of $133(33.08 \%)$ animals aged 5 to 10 years, 120 of $597(20.10 \%)$ animals aged over 10 years, 62 of 302 (20.53\%) Peulh of Sahel zebu, 86 of 242 (35.54\%) Bororo/Fulani zebu, and 16 of 192 (8.33\%) Toupouri-Massa zebu.

However, 68.57\% (95\% CI: 61.69-75.45) of 175 randomly selected cattle were positive for anti-bovine $\mathrm{Tb}$ antibodies with lateral flow assay. Single intradermal comparative cervical tuberculin (SICCT) skin test done on 86 of these 175 cattle showed 30 (35.29\%, 95\% CI: 25.1-45.4), 25 (29.41\%, 95\% CI: 19.7-39.1), 22 (25.88\%, 95\% CI: 16.6-35.2), 21 (24.7\%, 95\% CI: $15.5-33.8)$, and 18 (21.18\%, 95\% CI: 12.5-29.8) positive reactors at $\geq 2 \mathrm{~mm}, \geq 2.5 \mathrm{~mm}, \geq 3 \mathrm{~mm}, \geq 3.5 \mathrm{~mm}$, and $\geq 4 \mathrm{~mm}$ cut-off points, respectively. Of the 86 animals, Tb lesions and $\mathrm{Tb}$ lesions plus acid fast bacilli were detected in 28 animals (32.95\%, 95\% CI: 22.95-42.93) and 19 animals (22.35\%, 95\% CI: $13.5-31.2$ ), respectively. Over $73.26 \%$ (63) of the 86 SICCT animals were positive for anti-bovine $\mathrm{Tb}$ antibodies corresponding to apparent rates of 3.49\%, 31.40\%, 29.07\%, 25.58\%, $24.42 \%$, and $20.93 \%$ animals positive for SICCT bovine $\mathrm{Tb}$ and anti-bovine $\mathrm{Tb}$ antibody at $<2 \mathrm{~mm}, \geq 2 \mathrm{~mm}, \geq 2.5 \mathrm{~mm}$, $\geq 3 \mathrm{~mm}, \geq 3.5 \mathrm{~mm}$, and $\geq 4 \mathrm{~mm}$ cut-off points, respectively.

\subsection{Diagnostic Performance of Tuberculin Skin Test to Detect} Bovine Tuberculosis in Cattle. The performances of SICCT technique at various cut-off points to diagnose bovine $\mathrm{Tb}$ in cattle in Maroua, Cameroon, using detection of $\mathrm{Tb}$ lesions and detection of $\mathrm{Tb}$ lesions accompanied with acid fast bacilli in the lesions as references for defining the status disease are shown in Table 1. Based on computed sensitivity and specificity values of SICCT compared to detection of $\mathrm{Tb}$ lesions and $\mathrm{Tb}$ lesions plus acid fast bacilli, severe interpretations of SICCT tests detected more diseases cases. Though highest detection of disease cases by SICCT tests was detected at $\geq 2.0 \mathrm{~mm}$ cut-off point, the overall performances were superior at $\geq 3 \mathrm{~mm}$ and $\geq 3.5 \mathrm{~mm}$ cut-off values. The sensitivity of SICCT at $\geq 3 \mathrm{~mm}$ and $\geq 3.5 \mathrm{~mm}$ cut-off points compared to the sensitivity at $\geq 4 \mathrm{~mm}$ cut-off was not significantly higher $[P>0.05]$ against detection of $\mathrm{Tb}$ lesions but significantly higher $[P<0.05]$ against detection of Tb lesions plus acid fast bacilli to define disease status.

It is worth mentioning that overall the predictive values were usually superior at SICCT $\geq 3 \mathrm{~mm}$ and $\geq 3.5 \mathrm{~mm}$ cut-off points compared to the OIE recommended ( $\geq 4 \mathrm{~mm}$ ) cut-off point. Indeed, the performance of SICCT against detection of $\mathrm{Tb}$ lesions revealed positive predictive values of 73.3 (63.982.7); 80.0 (71.5-88.5); 86.3 (78.9-93.6); 90.4 (84.1-96.6); 88.8 (82.1-95.5) and negative predictive values of $89.0(82.3-$ 95.6); 86.6 (79.3-93.8); 85.7 (78.2-93.1); 85.9 (78.5-93.2); 82.0 (73.8-90.1) at reactors at $\geq 2 \mathrm{~mm}, \geq 2.5 \mathrm{~mm}, \geq 3 \mathrm{~mm}, \geq 3.5 \mathrm{~mm}$, and $\geq 4 \mathrm{~mm}$ cut-off points, respectively. Accordingly, the performance of SICCT against detection of Tb lesions plus acid fast bacilli revealed positive predictive values of 63.3 (53.05-73.54); 72 (62.45-81.54); 77.3 (68.39-86.20); 81 (72.66$89.34) ; 77.8$ (68.96-86.63) and negative predictive values of 100 ; 98.3 (95.5-100); 96.8 (93-100); 96.9 (93-100); 92.5 (86.998.1).

Furthermore, the ROC (Receiving Operating Characteristic) analysis showed that the area under the curve was significantly higher at cut-off points $<4 \mathrm{~mm}$, particularly at $\geq 3.5 \mathrm{~mm}$ cut-off point according to detection of $\mathrm{Tb}$ lesions [0.822 (0.711-0.932)] and detection of Tb lesions plus acid fast bacilli in the lesions [0.92 (0.83-1)] [Figure 1]. The area under the ROC curves according to detection of $\mathrm{Tb}$ lesions for all SICCT cut-off points was between 0.7 and 0.9 suggesting that these cut-off values are only fairly informative for the detection of bovine Tb. However, SICCT at $\geq 3.5 \mathrm{~mm}$ cut-off point showed significantly higher $(P<0.001)$ discriminatory power compared to SICCT at $\geq 4 \mathrm{~mm}$ cut-off point. For the ROC curves according to detection of detection of $\mathrm{Tb}$ lesions plus acid fast bacilli in the lesions, all SICCT cut-off points $<4 \mathrm{~mm}$ were between 0.9 and 1 , particularly for $\geq 3 \mathrm{~mm}$ and $\geq 3.5 \mathrm{~mm}$ cut-off points, indicating that these cut-off values are very informative for the detection of bovine $\mathrm{Tb}$. Therefore, the ROC findings also confirmed severe interpretations of SICCT bovine $\mathrm{Tb}$ detection [particularly at $\geq 3 \mathrm{~mm}$ and $\geq 3.5 \mathrm{~mm}$ cut-off points] as for sensitivity and specificity evaluations.

\section{Discussion}

The detection rates of macroscopic Tb lesions [22.28-32.95\%] in cattle in this study are much higher than values, ranging from $<1$ to $4.25 \%$, reported in the littoral and western highland regions of Cameroon [29, 42], while the prevalence of anti-bovine $\mathrm{Tb}$ antibodies [68.57\% and 73.26\%] was higher than $60 \%$ recorded in the Bamenda area [42] and $37.17 \%$ recorded in the highland regions [43]. Also, significantly higher SICCT bovine $\mathrm{Tb}$ prevalence estimates based on tuberculin skin tests at cut-off points $\geq 4 \mathrm{~mm}, \geq 3 \mathrm{~mm}$, and $\geq 2 \mathrm{~mm}$ were obtained compared to $3.59 \%-7.48 \%, 8.92 \%-$ $13.25 \%$, and $11.77 \%-17.26 \%$ recorded by Awah-Ndukum et al. [43] in the highland regions. However, the rates of SICCT bovine $\mathrm{Tb}$ /anti-bovine $\mathrm{Tb}$ antibodies animal responses in this study agree with that of Awah-Ndukum et al. [43] who reported that the proportion of SICCT bovine Tb/antibovine $\mathrm{Tb}$ antibody reactors was significantly higher at the $\geq 2 \mathrm{~mm}$ followed by the $\geq 3 \mathrm{~mm}$ and $\geq 4 \mathrm{~mm}$ cut-off point groups. These findings suggest that bovine $\mathrm{Tb}$ is highly endemic in cattle in the Maroua area compared to other parts of Cameroon and require severe interpretations of SICCT bovine $\mathrm{Tb}$ results.

Postmortem examination of $\mathrm{Tb}$ lesions and demonstration of acid fast bacilli by direct microscopy were used in this study to define disease status of bovine $\mathrm{Tb}$ in cattle, to evaluate the performance of tuberculin skin test as opposed to bacteriological culture that was used elsewhere as reference diagnostic test [13]. However, detection of Tb lesions showed lower sensitivity values compared to detection of $\mathrm{Tb}$ lesions accompanied with demonstration of acid fast bacilli in the lesions. Macroscopic examination of Tb lesions and demonstration of acid fast bacilli have also been used by Ameni et al. [15] in Ethiopia and Ngandolo et al. [21] in Chad to evaluate the diagnostic performances of tuberculin skin tests. In this study optimal detection of bovine $\mathrm{Tb}$ in cattle in Maroua, Cameroon, was obtained at severe interpretations of SICCT and particularly at $\geq 3 \mathrm{~mm}$ and $\geq 3.5 \mathrm{~mm}$. These findings are similar to those of Ameni et al. [15] who reported that 


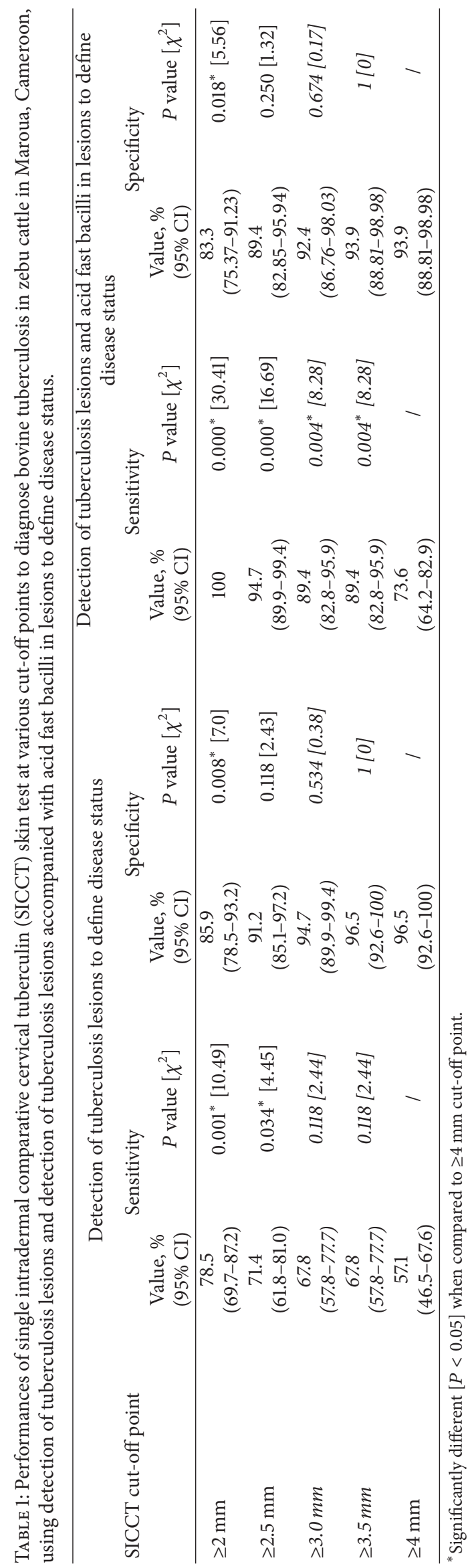



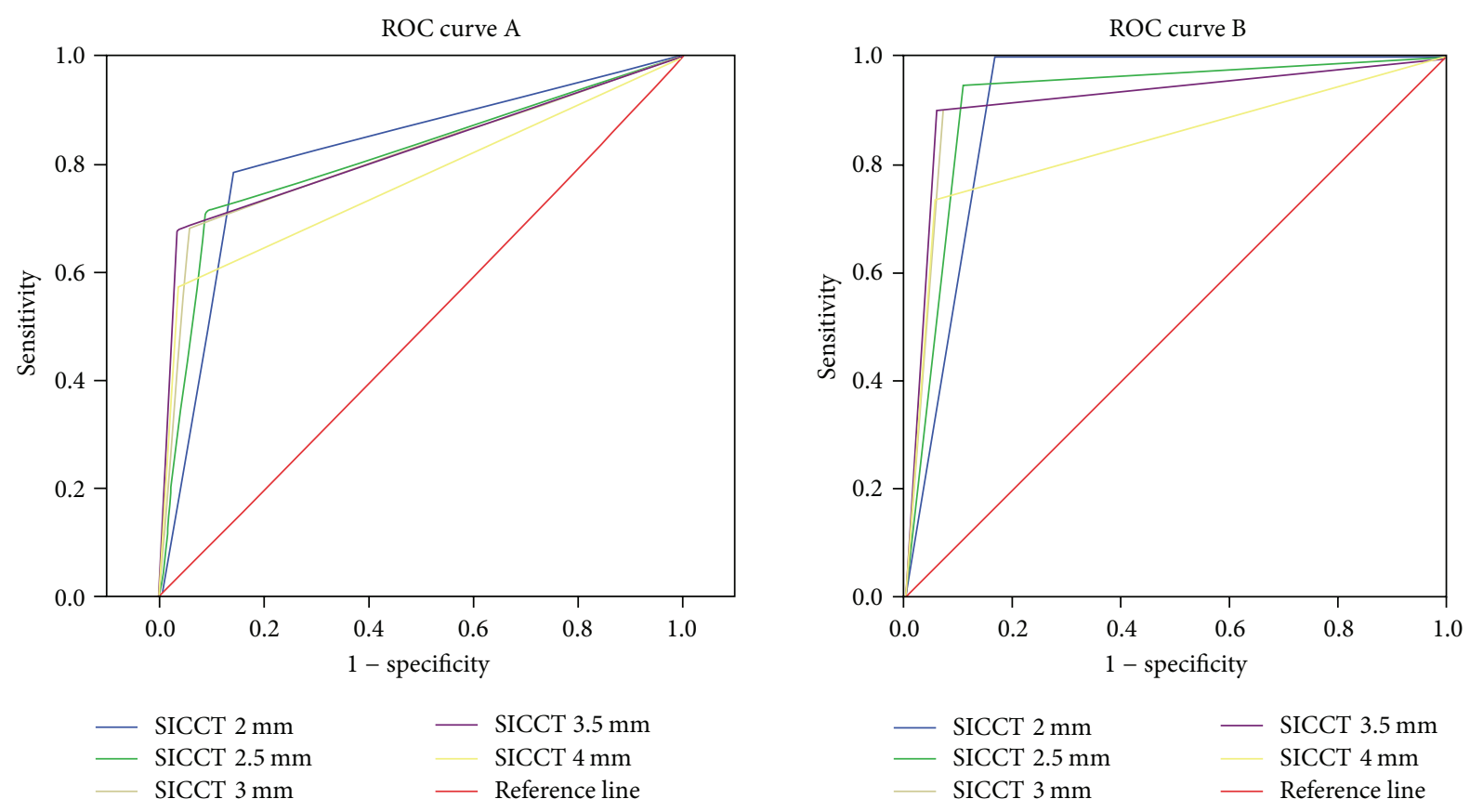

\begin{tabular}{lcc}
\hline $\begin{array}{l}\text { Skin cut-off } \\
\text { points }\end{array}$ & $\begin{array}{c}\text { Area under curve } \\
(\text { CI: } 95 \%)\end{array}$ & $\begin{array}{c}\text { Asymptomatic } \\
\text { significant }\end{array}$ \\
\hline SICCT $\geq 2 \mathrm{~mm}$ & $0.811(0.720-0.926)$ & 0.000 \\
SICCT $\geq 2.5 \mathrm{~mm}$ & $0.813(0.704-0.922)$ & 0.000 \\
SICCT $\geq 3 \mathrm{~mm}$ & $0.813(0.701-0.925)$ & 0.000 \\
SICCT $\geq 3.5 \mathrm{~mm}$ & $0.822(0.711-0.932)$ & 0.000 \\
SICCT $\geq 4 \mathrm{~mm}$ & $0.768(0.647-0.890)$ & 0.000 \\
\hline
\end{tabular}

\begin{tabular}{lcc}
\hline $\begin{array}{l}\text { Skin cut-off } \\
\text { points }\end{array}$ & $\begin{array}{c}\text { Area under curve } \\
(\text { CI: 95\%) }\end{array}$ & $\begin{array}{c}\text { Asymptomatic } \\
\text { significant }\end{array}$ \\
\hline SICCT $\geq 2 \mathrm{~mm}$ & $0.90(0.86-0.97)$ & 0.000 \\
SICCT $\geq 2.5 \mathrm{~mm}$ & $0.90(0.85-0.99)$ & 0.000 \\
SICCT $\geq 3 \mathrm{~mm}$ & $0.91(0.82-1)$ & 0.000 \\
SICCT $\geq 3.5 \mathrm{~mm}$ & $0.92(0.83-1)$ & 0.000 \\
SICCT $\geq 4 \mathrm{~mm}$ & $0.84(0.71-0.96)$ & 0.000 \\
\hline
\end{tabular}

FIgURE 1: ROC (Receiving Operating Characteristic) analysis of the performances of SICCT to detect bovine Tb. Classification of the single intradermal comparative cervical tuberculin (SICCT) skin test cut-off point performance with detection of tuberculous lesions as reference test (curve A). Classification of the single intradermal comparative cervical tuberculin (SICCT) skin test cut-off point performance with detection of tuberculous lesions and acid fast bacilli as reference test (curve B).

improved diagnostic performances of tuberculin skin test in zebu cattle in Ethiopia were obtained at severe interpretations of $>2 \mathrm{~mm}$ cut-off point. In Chad, Ngandolo et al. [21] also stated that optimum diagnostic performance of tuberculin skin test in Arab zebus and Bororo zebus was $>2 \mathrm{~mm}$ cut-off point. The present results agree with those of Awah-Ndukum et al. [43] who observed that improved diagnosis of bovine $\mathrm{Tb}$ by tuberculin skin test was obtained at $\geq 3 \mathrm{~mm}$ cut-off when compared to anti-bovine $\mathrm{Tb}$ antibody detection in Goudali, Red Bororo, and White Fulani zebus and their crosses in the highlands [Adamawa and Northwest] of Cameroon.

The tuberculin skin tests are currently the best available and affordable techniques for international field diagnosis of bovine TB in live animals $[14,24]$. Also, the tests are based on delayed hypersensitivity reactions [13]. The intradermal comparative cervical tuberculin (ICCT) skin test involving the intradermal injection of bovine tuberculin (BT) and avian tuberculin (AT) at separate sites in the skin of the neck gives more specific results than the simple intradermal tuberculin (SIT) skin test which uses only BT $[16,17]$. The World
Organisation for Animal Health (OIE) recommended difference between the increases in skin thickness for the test to be positive should be $>4 \mathrm{~mm}$ after 72 hours [13]. However, the OIE recommended cut-off value was established mainly in developed countries for Bos taurus cattle [15], in an epidemiologic context of very low prevalence of bovine $\mathrm{Tb}$ $[\leq 0.1 \%]$ and the implementation of a strict test and slaughter eradication policy [24]. Indeed, different cut-off values have been applied worldwide according to a particular country's disease status and objective of its disease control programme [17]. In Africa, for example, the $>2 \mathrm{~mm}, \geq 3 \mathrm{~mm},>4 \mathrm{~mm}$, and $\geq 4 \mathrm{~mm}$ cut-off points have been used in Chad, Ethiopia, and Tanzania $[15,17,22,23,44]$.

The ROC analysis and sensitivity evaluations support severe interpretation of tuberculin skin tests in this study, particularly at $\geq 3 \mathrm{~mm}$ and $\geq 3.5 \mathrm{~mm}$ cut-off points and [43] had proposed severe interpretations of tuberculin skin tests for the diagnosis of bovine $\mathrm{Tb}$ in Bos indicus cattle in Cameroon, where the prevalence of bovine $\mathrm{Tb}$ is high and widespread. The performance of tuberculin skin tests has also 
been affected by environmental factors, host factors (status of immunity, genetics, etc.), prevalence of the disease in the population tested, and the nature of the tuberculin used [1419]. A perfect cut-off point in a specific geographic area may not be so useful at another environment [14,17] and the ability of the test to accurately predict the true positive disease status depends on its sensitivity, specificity, and prevalence of the disease in the population tested [14]. Excessively high sensitivity of tuberculin skin tests will generate false positive reactions during interpretations of test results. However, severe interpretations for improved diagnosis have been done in regions or herds where $M$. bovis infection had been confirmed based on the discretion of the veterinarian [17].

In this study, the best individual sensitivity [67.8\% (57.877.7 ) at $\geq 3.5 \mathrm{~mm}$ cut-off point] of tuberculin skin test, with detection of $\mathrm{Tb}$ lesions as the reference test, recorded is lower than the median individual sensitivity [80\% (52.0-100)] stated by OIE [13] at the recommended $>4 \mathrm{~mm}$ cut-off point [14]. The best individual sensitivity [89.4\% (82.8-95.9) at $\geq 3.5 \mathrm{~mm}$ cut-off point] of tuberculin skin test, with detection of $\mathrm{Tb}$ lesions plus acid fast bacilli in lesions as the reference test, recorded is higher than the median individual sensitivity stated by OIE at the recommended cut-off point. The OIE proposed value is a median from a very wide dispersion (52.0-100\%) compared to very narrower dispersions for best overall values in the present study $(57.8-77.7 \%$ and $82.8-$ 95.9\%). For SICCT bovine Tb detection, the study showed higher (nonsignificant for detection of $\mathrm{Tb}$ lesions and significant for detection of $\mathrm{Tb}$ lesions accompanied with AFB in lesions as gold standards) sensitivities at severe $(<4 \mathrm{~mm}$ cut-off) interpretation compared to interpretation at the OIE recommended $(\geq 4 \mathrm{~mm})$ cut-off value. Severe interpretation of SICCT results diagnosed more bovine $\mathrm{Tb}$ cases and is very essential in managing high zoonotic potential [1] as well as high socioeconomic and cultural implication [45] of bovine $\mathrm{Tb}$ in Cameroon. The sensitivities obtained in this study are similar to the values of Ameni et al. [15] who reported $68.8 \%$ at $>2 \mathrm{~mm}$ cut-off point in Ethiopia and Delafosse et al. [23] who reported $94 \%$ at $\geq 4 \mathrm{~mm}$ in Chad. Various factors can influence the sensitivity of tuberculin skin test and the hypersensitivity reactions can fluctuate considerably depending on the animal. Delayed hypersensitivity reactions provoked by tuberculin injection can become established 3 to 6 weeks after exposure of the host to bacilli agents while recently infected animals may not react sufficiently to tuberculin injection [46]. The reaction is reduced in young animals [calves] and pregnant females [cow] near term [47].

Anergy has been reported to cause false negative reactions during tuberculin skin test but the reasons are still poorly understood [48]. However, recently infected cattle, cattle under stress due to malnutrition, gastrointestinal parasitoses, other concurrent infections, and cattle with generalized $\mathrm{Tb}$ would be anergic and fail to react to tuberculin skin test $[47,48]$. Therefore, cattle presenting differential SICCT skin thickness of $\leq 4 \mathrm{~mm}$ should not be excluded that they are not affected by bovine $\mathrm{Tb}$, especially animals in highly endemic areas and animals sensitized to environmental mycobacteria such as in Cameroon [29]. These animals could actually be infected but low reacting or not reacting at all because their immune systems may not be sufficiently stimulated for a positive response to occur at the $\geq 4 \mathrm{~mm}$ OIE recommended cut-off point $[47,48]$. Also, conditions such as stress may compromise their immune function [49] and animals may be sensitized to environmental mycobacteria [50]. Furthermore, in late stages or towards the end of the course of the disease, the capacities of the infected hosts may become saturated and the expected hypersensitivity reactions may not be observed [51]. Also, 1-5\% of some animals may be totally anergic during their entire lifespan $[24,52]$. These phenomena are responsible for the fluctuating sensitivities of tuberculin skin tests according to environments and amongst animal populations.

This study revealed that severe interpretation of tuberculin skin tests, at cut-off values less than the OIE recommended cut-off value of $>4 \mathrm{~mm}$, is essential for optimal diagnosis of bovine $\mathrm{Tb}$ in Bos indicus cattle in Maroua, Cameroon. The interpretations should be done at either $\geq 3 \mathrm{~mm}$ or $\geq 3.5 \mathrm{~mm}$ cut-off points given the epidemiological and environmental context of the region.

\section{Competing Interests}

The authors declare that they have no competing interests.

\section{References}

[1] J. Awah-Ndukum, A. C. Kudi, G. S. Bah, G. Bradley, V. NguNgwa, and P. L. Dickmu, "Risk factors analysis and implications for public health of bovine tuberculosis in the highlands of Cameroon," Bulletin of Animal Health and Production in Africa, vol. 62, no. 4, pp. 353-376, 2014.

[2] A. R. Boukary, E. Thys, S. Mamadou et al., "La tuberculose à Mycobacterium bovis en Afrique subsaharienne," Annales de Médecine Vétérinaire, vol. 155, pp. 23-37, 2011.

[3] C. H. Collins and J. M. Grange, "Zoonotic implication of Mycobacterium bovis infection," Irish Veterinary Journal, vol. 41, pp. 363-366, 1987.

[4] O. Cosivi, J. M. Grange, C. J. Daborn et al., "Zoonotic tuberculosis due to Mycobacterium bovis in developing countries," Emerging Infectious Diseases, vol. 4, no. 1, pp. 59-70, 1998.

[5] E. Etter, P. Donado, F. Jori, A. Caron, F. Goutard, and F. Roger, "Risk analysis and bovine tuberculosis, a re-emerging zoonosis," Annals of the New York Academy of Sciences, vol. 1081, pp. 6173, 2006, Impact of Emerging Zoonotic Diseases on Animal Health: 8th Biennial Conference of the Society for Tropical Veterinary Medicine.

[6] G. Moda, C. J. Daborn, J. M. Grange, and O. Cosivi, "The zoonotic importance of Mycobacterium bovis," Tubercle and Lung Disease, vol. 77, no. 2, pp. 103-108, 1996.

[7] C. Thoen, P. LoBue, and I. de Kantor, "The importance of Mycobacterium bovis as a zoonosis," Veterinary Microbiology, vol. 112, no. 2-4, pp. 339-345, 2006.

[8] J. E. Shitaye, W. Tsegaye, and I. Pavlik, "Bovine tuberculosis infection in animal and human populations in Ethiopia: a review," Veterinarni Medicina, vol. 52, no. 8, pp. 317-332, 2007.

[9] J. Awah-Ndukum, A. C. Kudi, G. Bradley et al., "Molecular genotyping of Mycobacterium bovis isolated from cattle tissues in the North West Region of Cameroon," Tropical Animal Health and Production, vol. 45, no. 3, pp. 829-836, 2013. 
[10] F. Koro-Koro, E. F. Bouba, A. F. Ngatchou, S. Eyangoh, and F.$\mathrm{X}$. Etoa, "First insight into the current prevalence of bovine tuberculosis in cattle slaughtered in Cameroon: the case of main abattoirs of Yaoundé and Douala," British Microbiology Research Journal, vol. 3, no. 3, pp. 272-279, 2013.

[11] S. N. Niobe-Eyangoh, C. Kuaban, P. Sorlin et al., "Genetic biodiversity of Mycobacterium tuberculosis complex strains from patients with pulmonary tuberculosis in Cameroon," Journal of Clinical Microbiology, vol. 41, no. 6, pp. 2547-2553, 2003.

[12] F. Nkongho, R. Kelly, L. Ndip et al., "Molecular epidemiology of bovine tuberculosis in Cameroon," in Proceedings of the 6th International M. Bovis Conference, Cardiff, UK, 2014.

[13] OIE, Manual of Diagnostic Tests and Vaccines for Terrestrial Animals 2009, OIE Terrestrial Manual 2008, World Organisation for Animal Health, Paris, France, 2009, http://www.oie.int/eng/normes/mmanual/A_summry.htm.

[14] R. T. Goodchild, M. Vordermeier, R. Clifton-Hadley, and R. de la Rua-Domenech, "Ante mortem diagnosis of Bovine Tuberculosis: the significance of unconfirmed test reactors," Government Veterinary Journal, vol. 16, no. 1, pp. 65-71, 2006.

[15] G. Ameni, G. Hewinson, A. Aseffa, D. Young, and M. Vordermeier, "Appraisal of interpretation criteria for the comparative intradermal tuberculin test for diagnosis of tuberculosis in cattle in central Ethiopia," Clinical and Vaccine Immunology, vol. 15, no. 8, pp. 1272-1276, 2008.

[16] J. Francis, C. L. Choi, and A. J. Frost, "The diagnosis of tuberculosis in cattle with special reference to bovine PPD tuberculin," Australian Veterinary Journal, vol. 49, no. 5, pp. 246-251, 1973.

[17] M. L. Monaghan, M. L. Doherty, J. D. Collins, J. F. Kazda, and P. J. Quinn, "The tuberculin test," Veterinary Microbiology, vol. 40, no. 1-2, pp. 111-124, 1994.

[18] T. Marcotty, F. Matthys, J. Godfroid et al., "Zoonotic tuberculosis and brucellosis in Africa: neglected zoonoses or minor public-health issues? The outcomes of a multi-disciplinary workshop," Annals of Tropical Medicine and Parasitology, vol. 103, no. 5, pp. 401-411, 2009.

[19] M.-F. Humblet, M. Gilbert, M. Govaerts, M. Fauville-Dufaux, K. Walravens, and C. Saegerman, "New assessment of bovine tuberculosis risk factors in Belgium based on nationwide molecular epidemiology," Journal of Clinical Microbiology, vol. 48, no. 8, pp. 2802-2808, 2010.

[20] S. A. J. Strain, M. James, and W. J. M. Stanley, "Bovine tuberculosis: a review of diagnostic tests for M. bovis infection in cattle," Bacteriology Branch Veterinary Sciences Division, AgriFood and Biosciences Institute, vol. 45, pp. 8-23, 2011.

[21] B. N. Ngandolo, C. Diguimbaye-Djaibé, B. Müller et al., "Diagnostics ante et post mortem de la tuberculose bovine au sud du Tchad: cas des bovins destinés à l'abattage," Revue d'Élevage et de Médecine Vétérinaire des Pays Tropicaux, vol. 62, no. 1, pp. 5-12, 2009.

[22] R. R. Kazwala, D. M. Kambarage, C. J. Daborn, J. Nyange, S. F. H. Jiwa, and J. M. Sharp, "Risk factors associated with the occurrence of bovine tuberculosis in cattle in the Southern Highlands of Tanzania," Veterinary Research Communications, vol. 25, no. 8, pp. 609-614, 2001.

[23] A. Delafosse, F. Goutard, and E. Thébaud, "Epidémiologie de la tuberculose et de la brucellose des bovins en zone périurbaine d'Abéché, Tchad," Revue d'Élevage et de Médecine Vétérinaire des Pays Tropicaux, vol. 55, no. 1, pp. 5-13, 2002.

[24] R. de la Rua-Domenech, A. T. Goodchild, H. M. Vordermeier, R. G. Hewinson, K. H. Christiansen, and R. S. Clifton-Hadley,
"Ante mortem diagnosis of tuberculosis in cattle: a review of the tuberculin tests, $\gamma$-interferon assay and other ancillary diagnostic techniques," Research in Veterinary Science, vol. 81, no. 2, pp. 190-210, 2006.

[25] J. M. Pollock, J. McNair, H. Bassett et al., "Specific delayed-type hypersensitivity responses to ESAT-6 identify tuberculosisinfected cattle," Journal of Clinical Microbiology, vol. 41, no. 5, pp. 1856-1860, 2003.

[26] M. Amadori, S. Tameni, P. Scaccaglia, S. Cavirani, I. L. Archetti, and R. Q. Giandomenico, "Antibody tests for identification of Mycobacterium bovis-infected bovine herds," Journal of Clinical Microbiology, vol. 36, no. 2, pp. 566-568, 1998.

[27] B. M. Buddle, P. G. Livingstone, and G. W. de Lisle, "Advances in ante-mortem diagnosis of tuberculosis in cattle," New Zealand Veterinary Journal, vol. 57, no. 4, pp. 173-180, 2009.

[28] M. L. Thom, J. C. Hope, M. McAulay et al., "The effect of tuberculin testing on the development of cell-mediated immune responses during Mycobacterium bovis infection," Veterinary Immunology and Immunopathology, vol. 114, no. 1-2, pp. 25-36, 2006.

[29] J. Awah-Ndukum, A. C. Kudi, G. Bradley et al., "Prevalence of bovine tuberculosis in cattle in the highlands of Cameroon based on the detection of lesions in slaughtered cattle and tuberculin skin tests of live cattle," Veterinarni Medicina, vol. 57, no. 2, pp. 59-76, 2012.

[30] M. Thrusfield, Veterinary Epidemiology, vol. 610 of Blackwell Publishing Company, Blackwell Science, Oxford, UK, 3rd edition, 2007.

[31] MINEPIA, "La stratégie sectoriel de l'élevage, des peches et industries animales," in Cabinet Management 2000 MINEPIA, A. Doufissa, Ed., Ministry of Livestock, Fisheries and Animal Industries, Yaounde, Yaounde, Cameroon, 2002.

[32] FAO, A Manual for the Primary Animal Health Care Worker, Food and Agriculture Organization of the United Nations, Rome, Italy, 1994.

[33] J. F. Gracey and D. S. Collins, Meat Hygiene, Bailliére Tindall, London, UK, 9th edition, 1992.

[34] A. Grist, Bovine Meat Inspection-Anatomy, Physiology and Disease Conditions, Nottingham University Press, Nottingham, UK, 2nd edition, 2008.

[35] J. Turton, How to Estimate the Age of Cattle, National Department of Agriculture, ARC-Onderstepoort Veterinary Institute, Pretoria, South Africa, 1999.

[36] R. Blench, Traditional Livestock Breeds: Geographical Distribution and Dynamics in Relation to the Ecology of West Africa, Overseas Development Institute, London, UK, 1999.

[37] M. J. Nicholson and M. H. Butterworth, A Guide to Condition Scoring of Zebu Cattle, International Livestock Centre for Africa, Addis Ababa, Ethiopia, 1986.

[38] C. Diguimbaye, M. Hilty, R. Ngandolo et al., "Molecular characterization and drug resistance testing of Mycobacterium tuberculosis isolates from Chad," Journal of Clinical Microbiology, vol. 44, no. 4, pp. 1575-1577, 2006.

[39] B. E. Strong and G. P. Kubica, Isolation and Identification of Mycobacterium Tuberculosis-A Guide for the Level II Laboratory, Department of Health and Human Services, Public Health Service, Laboratory Improvement Program Office, Division of Laboratory Training and Consultation Atlanta, Atlanta, Ga, USA, 1985.

[40] World Health Organization (WHO), Laboratory Services in Tuberculosis Control. Part III : Culture, World Health Organization (WHO), Geneva, Switzerland, 1998. 
[41] WHO, Laboratory Services in Tuberculosis Control Part II: Microscopy, World Health Organization, Geneva, Switzerland, 1998.

[42] J. Awah Ndukum, A. Caleb Kudi, G. Bradley, I. N. AneAnyangwe, S. Fon-Tebug, and J. Tchoumboue, "Prevalence of bovine tuberculosis in abattoirs of the littoral and western highland regions of cameroon: a cause for public health concern," Veterinary Medicine International, vol. 2010, Article ID 495015, 8 pages, 2010.

[43] J. Awah-Ndukum, A. C. Kudi, G. S. Bah et al., "Bovine tuberculosis in cattle in the highlands of cameroon: seroprevalence estimates and rates of tuberculin skin test reactors at modified cut-offs," Veterinary Medicine International, vol. 2012, Article ID 798502, 13 pages, 2012.

[44] B. N. R. Ngandolo, B. Müller, C. Diguimbaye-Djaïbe et al., "Comparative assessment of fluorescence polarization and tuberculin skin testing for the diagnosis of bovine tuberculosis in Chadian cattle," Preventive Veterinary Medicine, vol. 89, no. 1-2, pp. 81-89, 2009.

[45] J. Awah-Ndukum, K. J. P. Mingoas, V. Ngu Ngwa, M. G. V. Ndjaro Leng, and P. A. Zoli, "Causes and associated financial losses of carcass and organ condemnations in the SODEPA abattoir of Yaoundé, Cameroon," Global Veterinara, In press.

[46] J. Francis, "Susceptibility to tuberculosis and the route of infection," Australian Veterinary Journal, vol. 47, no. 9, p. 414, 1971.

[47] G. Ameni and G. Medhin, "Effect of gastro-intestinal parasitosis on tuberculin test for the diagnosis of bovine tuberculosis," Journal of Applied Animal Research, vol. 18, no. 2, pp. 221-224, 2000.

[48] F. O. Inangolet, B. Demelash, J. Oloya, J. Opuda-Asibo, and E. Skjerve, "A cross-sectional study of bovine tuberculosis in the transhumant and agro-pastoral cattle herds in the border areas of Katakwi and Moroto districts, Uganda," Tropical Animal Health and Production, vol. 40, no. 7, pp. 501-508, 2008.

[49] C. O. Thoen, P. A. LoBue, D. A. Enarson, J. B. Kaneene, and I. N. de Kantor, "Tuberculosis: a re-emerging disease of animals and humans," Veterinaria Italiana, vol. 45, no. 1, pp. 135-181, 2009.

[50] M. V. Palmer, W. R. Waters, T. C. Thacker, R. Greenwald, J. Esfandiari, and K. P. Lyashchenko, "Effects of different tuberculin skin-testing regimens on gamma interferon and antibody responses in cattle experimentally infected with Mycobacterium bovis," Clinical and Vaccine Immunology, vol. 13, no. 3, pp. 387394, 2006.

[51] A. W. Lepper, C. W. Pearson, and L. A. Corner, "Anergy to tuberculin in beef cattle," Australian Veterinary Journal, vol. 53, no. 5, pp. 214-216, 1977.

[52] J. M. Pollock and S. D. Neill, "Mycobacterium boviss infection and tuberculosis in cattle," The Veterinary Journal, vol. 163, no. 2, pp. 115-127, 2002. 

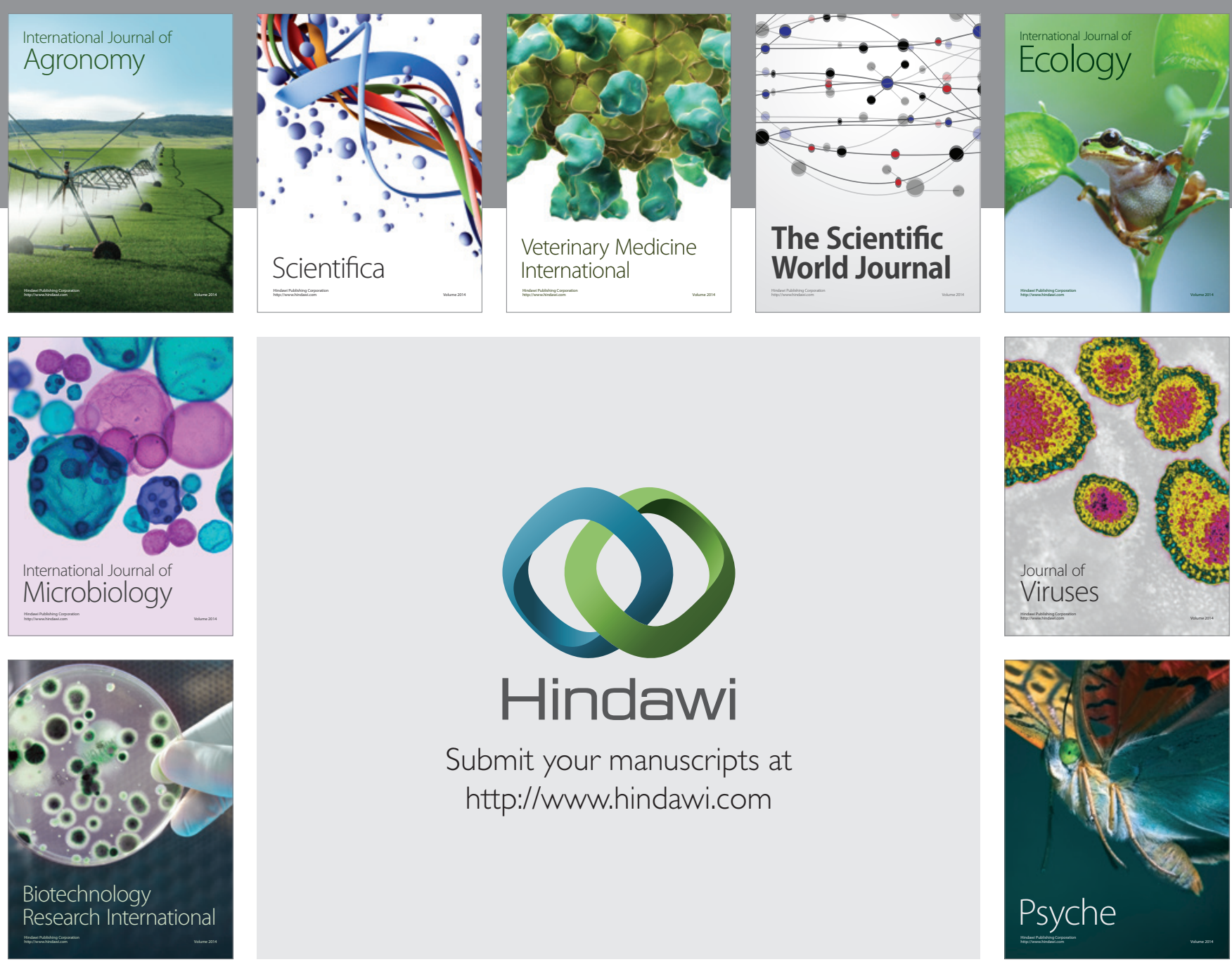

Submit your manuscripts at

http://www.hindawi.com
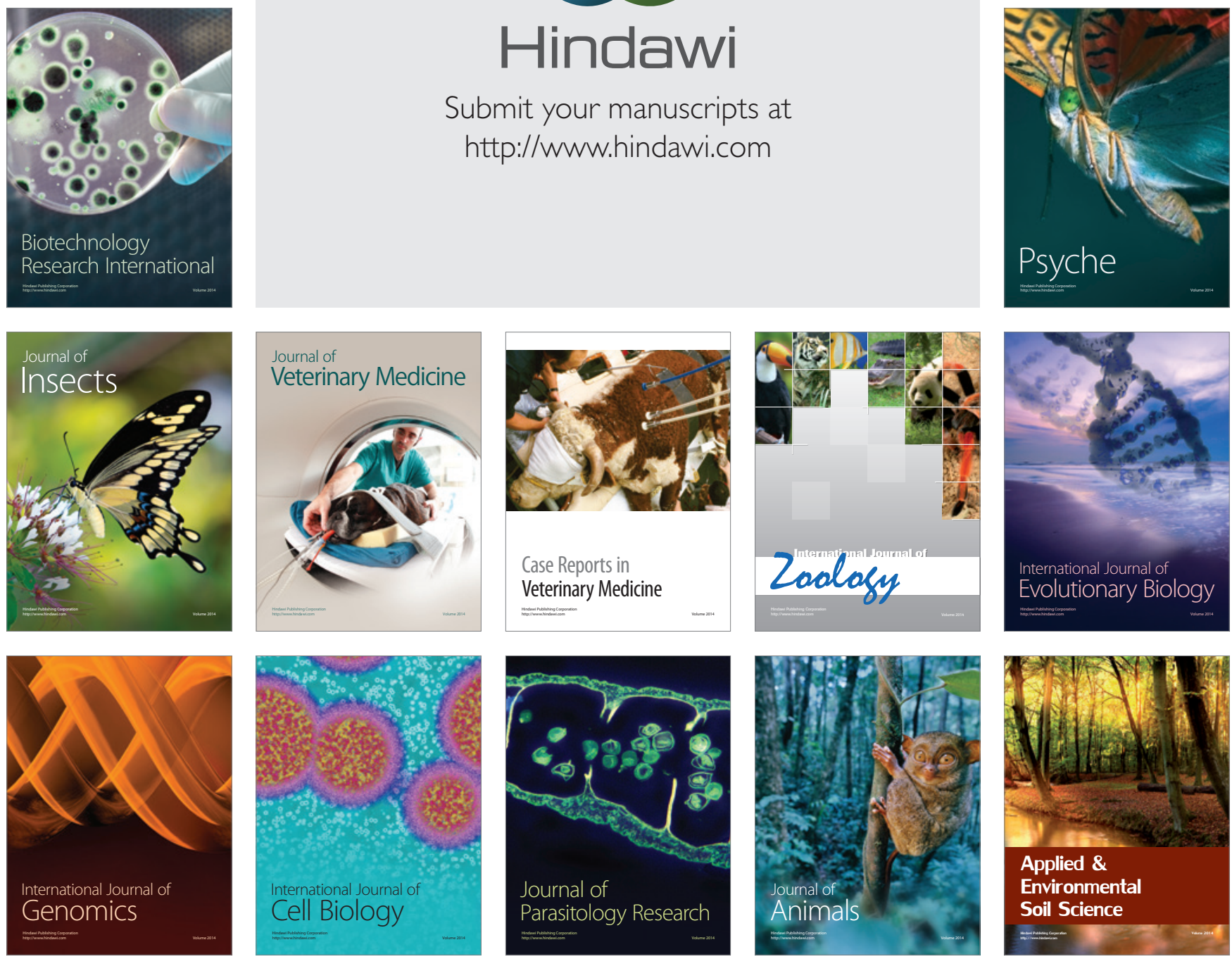